\title{
The Development of Online Education in Higher Education Industry of China
}

\author{
Yu Yuan ${ }^{1, a}$, Juan Liü ${ }^{1, b}$, Yuan Zhang ${ }^{1,2, c}$, Yan Lin ${ }^{1, d}$ \\ ${ }^{1}$ Shanghai International Studies University, Xianda College of Economics \& Humanities, Shanghai, \\ China \\ ${ }^{2}$ Chinese Academy of Social Sciences, Shanghai Academy, Shanghai, China \\ a0801020@xdsisu.edu.cn, b1301050@xdsisu.edu.cn, \\ c1601010@xdsisu.edu.cn, ${ }^{\mathrm{d}} 1202030 @ x d s i s u . e d u . c n$
}

Keywords: Online Education, Higher Education, Education Reform, Internet Concept

\begin{abstract}
The internet keeps updating our daily life including education methods. It is not necessary to sit in the classroom or attend the class in person to learn knowledge, lots of new methods of online teaching appeared these years which has impacted the higher education. Colleges and universities in China have tried several ways of online education, but the results are not good as the expectation. New ideas and ways are required to make sure the success of online education. In this article, the current situation of online education in China has been introduced, problems existing have been discussed and solutions have been provided.
\end{abstract}

\section{Introduction}

In recent years, the internet has changed a lot of things in our daily life. With its fast development, we can search whatever we want to know, we can order food whatever we want to eat, we can connect to others whoever we want to see. Regarding its contribution to the education, our development is that we can learn the courses anytime, anywhere. We can attend the class, no matter how far away it is from us. These new models of education are identified as 'Online Education'.

The development of Online Education should be based on the transformation of the personnel cultivation in the era of digital knowledge economy, which has a critical importance to today's education. Now we are in the society of the digital knowledge, the social development is based on the knowledge development and innovation creativity. The knowledge is in the presence of digits and network. The classroom-based way of teaching will lag behind the speed of knowledge growth and cannot adapt to the generation, dissemination and application of the networked knowledge. The traditional higher education is facing the trend of transforming from teaching face to face to online or mixed models.

The concepts of developing 'Internet ${ }^{+}$' in the new era to reform the higher education of colleges and universities is a hot topic now. An Innovative and new mechanism of cultivation proper talents is the aim and key problems of our teaching and education.

\section{The New Features of Online Education}

The current online education products can be categorized from different perspectives. From the perspective of the institutions main business, we can classify them as educational institutions and commercial institutions; from the perspective of the learners' educational levels, we can classify 
them as K12, vocational education, higher education and continuous education products; from the perspective of the service provided, we can classify them as resources, tool, platforms and other online educational products; from the perspective of the certificates, we can classify them as academic education and non-academic education.

With the continuous development of the internet technology and intelligent terminals, people can get access to the internet resources any time anywhere. Now the geographical restrictions on the educational resources have disappeared. The new model of online teaching and learning have been recognized and accepted well, which definitely, is a new reform of people's traditional learning patterns and habits.

Most of college and university students have been used to the way of teaching that teachers keep 'filling' them with knowledge. They learn passively as they won't have many chances of interaction with the teacher in class or after class due to various reasons. Now the online education finds a new way to keep the learning and teaching more attractive which has the following features.

- Open to share

Online education broke the traditional rule of teaching on a podium with a pen. People only need to have a computer or a mobile phone or a pad, maybe even just a TV in the future to have online courses anytime, anywhere. Students can take use of their fragmented learning time instead of sitting in the classroom continuously for 45-90 minutes. What's more, all the students registered for online course will get access to other peer learners resources such as their notes, their feedback and their homework which can help all the learners to generate new ideas. The learning process will no longer be a teacher teaching alone, it will be an internet based learning with lots of interactions. The online education will be more open and free to all the learners with no barriers of time or distance.

- Customized with autonomy

As it is easy to get access to massive learning resources on the internet, students can choose the courses according to their learning interest and availability. The learning plan and curriculum can be customized individually. For example, the NetEase is running an online class providing different videos which can be chosen according to learner's needs. Using the online model, not only the courses you chosen will be recorded in your own profile but also the learning process and behaviors will be recorded, tracked and analyzed with the technology of massive data analysis, which in return, will provide learners with better learning experience.

- Low cost with fairness

The online education is fair to those who can get access to the internet. The world's top education institutions and resources can be with you as long as you have the access. You can enjoy the excellent teachings and high-quality class without stepping out. You do not need to pay high tuition fees of going to a university or even overseas studies. This is quite fair to those students in less developed areas. Besides, the online education has no limitations of age, occupation, geographical problems or numbers of learners. The online education makes the boundaries between schools and society, schools and schools disappeared. More and more learners have the fair opportunities of the education.

\section{Practices of Online education in the Higher Education Industry}

The most popular online education model nowadays is 'MOOC', which enables learners to register and select the course, attend and participate in the class, submit the assignments and access to the credits online. Tsinghua University and Peking University are the most famous 
universities in China, they have developed their own online school in their website. Some other universities or colleges have chosen to cooperate with the local companies or business unions to develop a kind of online education platform.

However, most of the learners are less likely to revisit the website after their completion of their study. Research data showed that in 2013, the market share of online education dropped to 50\%. The number of potential students aged from 23-30 decreased in 2014-2015. Besides, the data showed that among all the MOOC registered learners, only 50\% had completed their selected courses. Despite the features and advantages brought by online education, the development situation of the online education is not so optimistic. New ideas and solutions are urgently required.

Actually, the online education has very strong internet nature, which requires decentralization, user orientation, and iterative logical thinking. If the we just use watching the digital videos online to take place of attending the class in person in the classroom, the reform of the online education will be doomed for failure. The online education needs to show the Internet+ characteristics with the expansion of the network thinking. We may assume that the reason why online education is not as good as expected is because the most design and the function of the courses are too simple and even boring, with no complementary products and services. The learners seldom gain the happiness and sense of achievements and will lose interest gradually.

\section{Suggestions and Solutions}

- Multi-dimensional cooperation

Colleges and universities have rich teaching resources and good at designing the learning process. The business companies and other social entities, they have advanced and professional Internet technology and rich capital. If the three parties can work together, the new cooperation model can be 'Knowledge+Technology+Capital'. In this way, the teaching quality, the technical support and the funds can be guaranteed which will result in a sustainable online education development.

- Optimize the teaching content

As we see, the online teaching has lots of advantages, therefore, it can help the colleges and universities to promote their brands, take most advantages of their teaching resources. However, if the colleges and universities want to be successful under this new model, it requires not only the carefully prepared teaching videos to be published online, but also the new concepts and teaching methods. Thus, in order to achieve the best results, the team will have professional lecturers, counselors, curriculum designers, photographers and IT experts together to be dedicated to the online program, transferring from lecturers teaching alone to a teamwork program.

- Innovative Higher Education Management System

Based on the current education management system, every college and university in China is operating independently which will cause the repetitive construction and waste of resources. Besides, the registration and certificates are managed by individual college or university will make it harder to share resources for online education. Facing the precious developing opportunities in the internet era, the government and colleges, universities can work together to break those management barriers.

- Develop new operation models

Most of the teaching and learning resources in the internet are very cheap or even free. But in 
the long term, the resources provided cannot be always free which definitely requires huge amount of capital to invest in. No matter the colleges or universities wish to develop the online teaching platform by themselves or cooperate with each other, we need to find continuous and stable funds. The current models are roughly two types, one is free operation. The profit will be generated from the advertisements on the website. The other one is free at the starting stage to cultivate users habit and occupy the market share. Once there are stable and mature users, it will charge the service fees. Other new models of operation are to be developed, such as higher quality, unique and precious teaching materials can be specially charged. More educational products values can be added according to the users' demand.

\section{Conclusions}

We cannot ignore the effects brought by the internet development and we need to take advantages of this new technology. The online education is not the substitute of the traditional teaching in the classroom. In China, the higher education is responsible for cultivating and educating learners to fully prepared for the future work and career developments. Thus, to keep the education with the pace of social developments is quite important. As the coming college or university learners are born after 2000, their learning habits and life styles are different and updating, our educators should work more on the integration of the traditional and online education methods.

\section{References}

[1] Li Qin, The Innovation Teaching Mode of Private Colleges in the Internet + Era, Higher Education Forum [J], 2016,29(10):13-14

[2] Liu Tao, Zheng Haihao, Reconstruction of Communication Systems of Online Higher

[3] Education in the Internet Era: Based on the Theory of Indirect Network Effects, China Academic Journal [J], 2016(4):42-48

[4] Li Hongyan, Liu Rong, Research on the Innovation of Teaching Mode in Colleges and Universities under the Background of "Internet+", China Computer \& Communication [J], 2017(6):240-241

[5] Guan Jia, Li Qitao, China’s Online Education Current Situation, Trend and Experience for Reference, Distance Education and Online Learning [J], 2014(8):62-66 